\title{
Performance Comparison of 8x10Gbps WDM System Using RZ and NRZ Format
}

\author{
Jasleen Kaur* $^{1}$, Jyotsana ${ }^{2}$ and Jyoteesh Malhotra ${ }^{3}$ \\ Department of Electronics and Communication Engg., GNDU \\ Regional Campus, Jalandhar-144008, Punjab.India \\ *Corresponding Author E-mail: jasleenkaur478@gmail.com
}

\begin{abstract}
In this paper, the performance analysis of $8 X 10$ Gbps WDM system for different data formats has been done. The performance is analyzed for Non return-to-zero (NRZ) and Return-to-Zero (RZ) modulation formats to find maximum transmission distance for 80Gbps WDM system. It has been found that for NRZ the system travel transmission distance of $962 \mathrm{~km}$ and for $R Z$ the system travel transmission distance of $1203 \mathrm{~km}$. The total of eight channels with data rate of $10 \mathrm{Gbps}$ and equal channel spacing of $300 \mathrm{GHZ}$ has been taken.
\end{abstract}

Keywords: RZ, NRZ, WDM

\section{Introduction}

The development of the wavelength division multiplexing (WDM) technique has opened new avenues for all-optical devices, which compensate for signal losses while performing data regeneration (i.e., dispersion compensation) with lower cost than its electronic counterpart. Wavelength division multiplexing (WDM) has become a preferred transmission technology in the transport network of long distance communication. The advances in optical communication have been promoted in part by development of efficient and powerful optical amplifiers which eliminate the need of costly converter from optical to electrical signal and vice-versa. Due to recent advance in wideband optical amplifiers, the communication is possible WDM system at terabit per second data rates. Optical communication uses very high frequencies light wave carries usually in THz. In order to maximize the use of available bandwidth in communication systems different multiplexing techniques are used, so that multiple users can access the bandwidth efficiently. The most commonly techniques are time division multiplexing, frequency division multiplexing, wavelength division multiplexing, optical code division multiplexing and dense wavelength division multiplexing. Most widely used multiplexing is the wavelength division multiplexing. WDM allows the users to share bandwidth according to the wavelengths assigned to them. This technique is one the most common techniques for optical communication. Dispersion limited distances for NRZ external modulated system at $10 \mathrm{Gbps}$ with $25 \mathrm{ghz}$ spacing is about $80 \mathrm{~km} \mathrm{[3].} \mathrm{For} 40 \mathrm{Gbps}$ wdm system single mode fiber can transmit optical signal over $720 \mathrm{~km}$ by optimizing optical and electrical filter characteristic at the receiver and by compensation of dispersion [1]. For the distances varying from $(5 \mathrm{~km}-100 \mathrm{~km})$ the return to zero pulse is efficient for longdistance, high bit rate [2].Optical fiber systems require hundred of consideration regarding design of fiber such as modulation scheme, type of fiber RZ offers better efficiency with respect to NRZ in single mode fiber [4]. Comparison of non return to zero and return to zero modulation format operating at data rate up to $40 \mathrm{Gbps}$ is evaluated. It is found that in 10-40 Gbps system single mode fiber alternating with dispersion compensated fiber, NRZ is more adversely affected by non-linearities, whereas RZ is more affected by dispersion [5]. With the increase in no. of channels and transmission distance the 
performance of the system degrade [6]. Although the bandwidth requirement of RZ is double than that of NRZ but its shape enables an increase in robustness to non linear effects and wide spectrum so it produces better result as compared to NRZ. RZ format is less susceptible to ISI, its modulation method is self synchronized, laser life time is prolonged, hence better performance [8].

\section{System Design}

The $8 \times 10$ Gbps WDM system is design to analyze the performance for different encoding techniques: Non-return to zero (NRZ) and Return to zero (RZ). The simulation tool used is optisystem v11.On transmitter side total 8 channels are multiplexed to make it travel over optical fiber. Each channel has data rate of $10 \mathrm{Gbps}$ with equal channel spacing of $300 \mathrm{GHZ}$. To compensate chromatic dispersion, dispersion compensating fiber is used. The block diagram of $8 \times 10 \mathrm{Gbps}$ WDM system is shown in Figure 1.The operating frequencies of channels are in the range from 193.1 THZ to 195.2 THZ. Each transmitter has a laser source, pseudo-random bit sequence, NRZ/RZ line encoder which goes to modulator (mach-zehnder) and then multiplexed .Then all of the 8 multiplexed signals are transmitted over single mode optical fibre having dispersion $16.75 \mathrm{ps} / \mathrm{nm}-\mathrm{km}$ along with DCF having dispersion $-80 \mathrm{ps} / \mathrm{nm}-\mathrm{km}$ for compensation. At reciever section, there are present 8 reciever block; ecah reciever block consist of PIN photodiode which convert the optical signal to an electrical signal, further followed by a Low-pass bessel filter, regenerator and eye diagram analyzer. Bessel filter and $3 \mathrm{R}$ regenerator are used to reconstruct the original signal. From the eye diagram analyzer the value of Q-Factor; average eye opening and BER can be analyzed at different modulation coding technique.

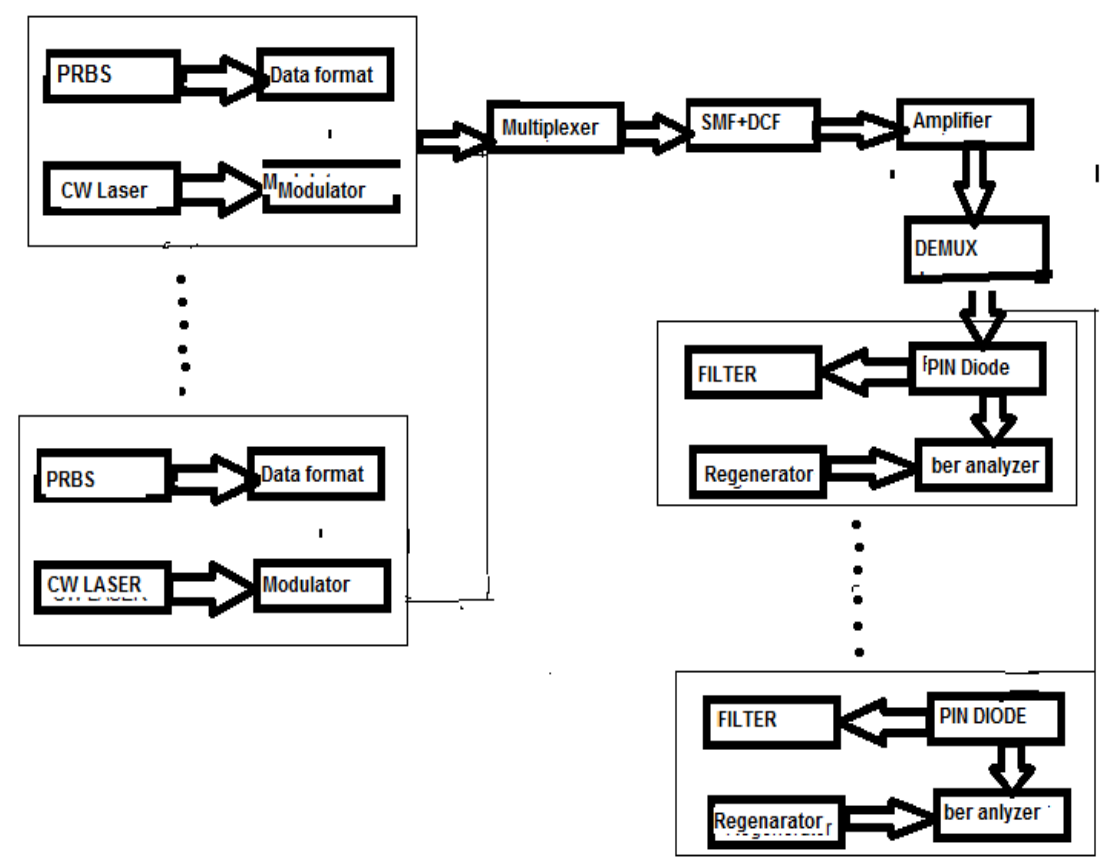

Figure 1. Block Diagram of 8x10 Gbps WDM System 


\section{Results \& Discussions}

\subsection{For NRZ Format}

A single mode fibre of length $40 \mathrm{~km}$ with dispersion of $16.75 \mathrm{ps} / \mathrm{nm}-\mathrm{km}$ and dispersion compensated fibre of length $8.13 \mathrm{~km}$ with dispersion of $-80 \mathrm{ps} / \mathrm{nm}-\mathrm{km}$ with 20 loops thus making total distance of $962 \mathrm{~km}$ is evaluated for NRZ format; where the pulse is on for the entire bit period.

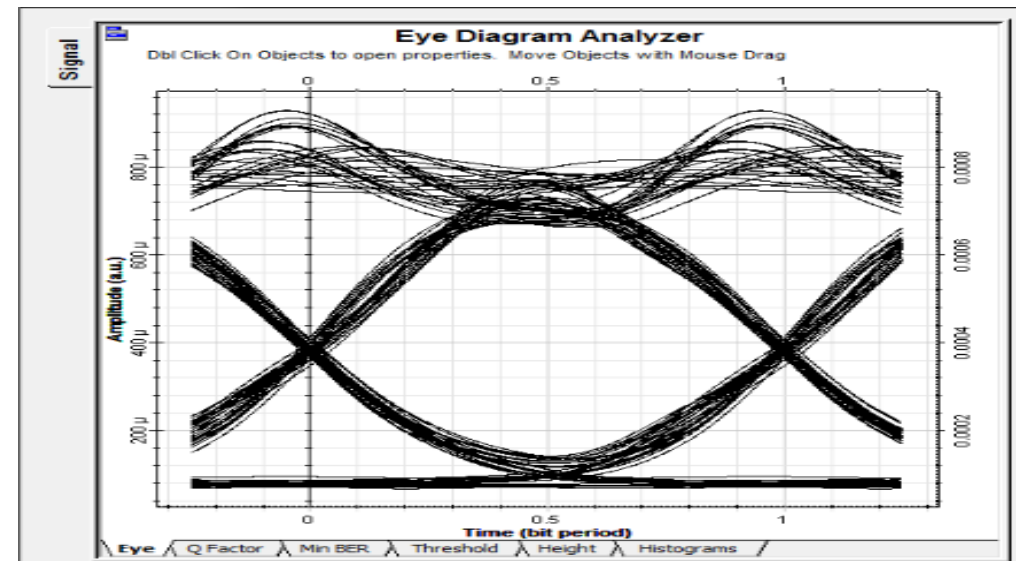

Figure 2. Eye Diagram at Channel 1

At frequency of $193.1 \mathrm{THz}$ the transmission distance of $962 \mathrm{~km}$ with Q-factor of 10.97and min. BER of $10^{-28}$ is achieved.

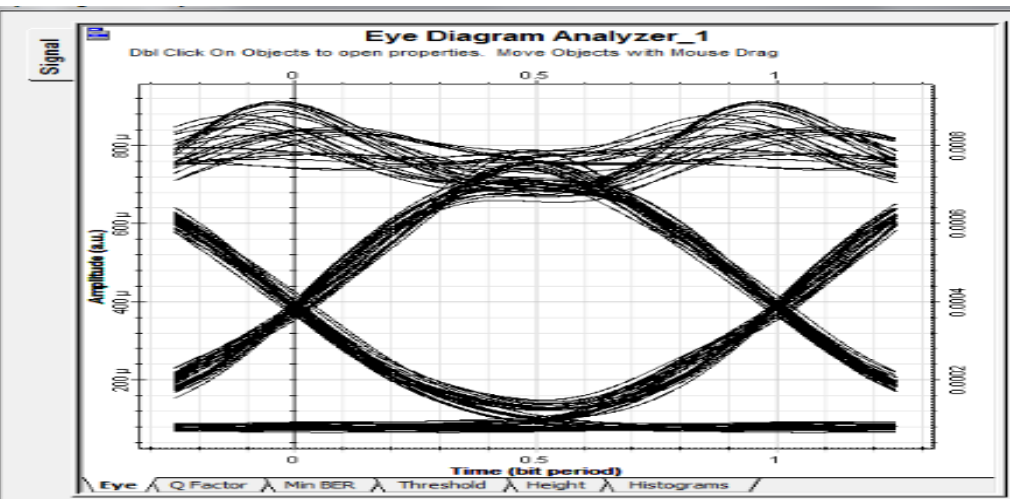

Figure 3. Eye Diagram at Channel 8

For frequency of 195.2 Thz at a transmission distance of $962 \mathrm{~km}$ Q- factor of 10.90 and $\min$ BER of $10^{-28}$ is achieved. 


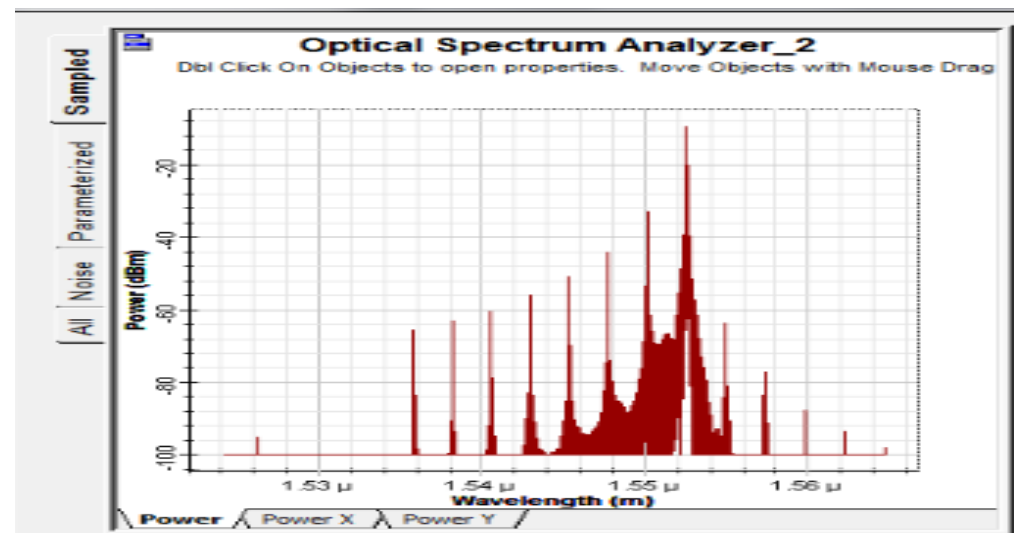

Figure 4. Optical Spectrum Analyzer for Channel 1 Operated at $193.1 \mathrm{THz}$

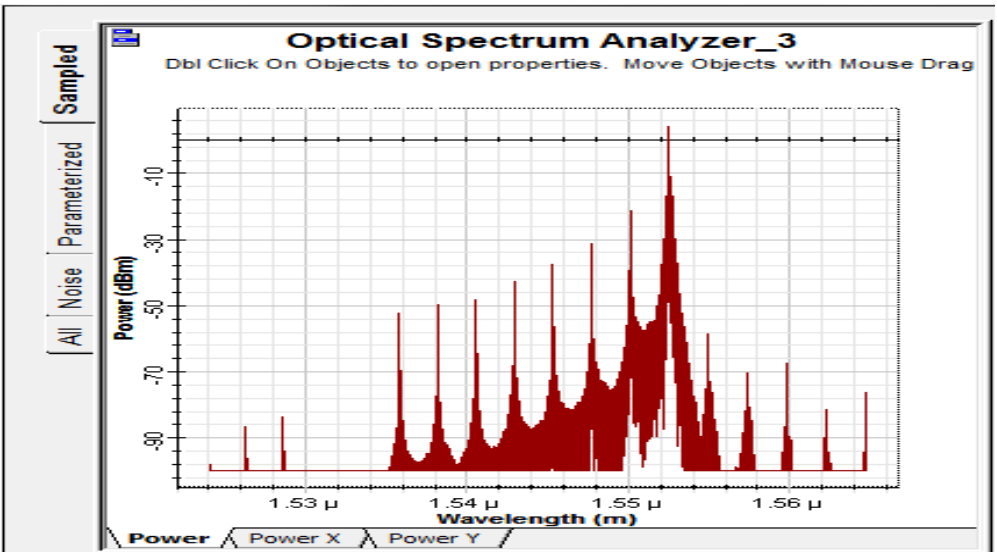

Figure 5. Optical Spectrum Analyzer for Channel 8 Operated at 195.2 THz

\subsection{For RZ Format}

A single mode fiber of length $40 \mathrm{~km}$ with dispersion of $16.75 \mathrm{ps} / \mathrm{nm}-\mathrm{km}$ and dispersion compensated fibre of $8.13 \mathrm{~km}$ with dispersion of $-80 \mathrm{ps} / \mathrm{nm}-\mathrm{km}$ with 25 loops thus making total distance of $1203 \mathrm{~km}$ is evaluated for all eight channels with duty cycle of each return to zero modulator being 0.5 in the designed wavelength division multiplexed system bit. In return-to-zero (RZ) format the pulse is on for only a portion of the bit period. RZ performs better than NRZ format as it is less susceptible to inter symbol interference

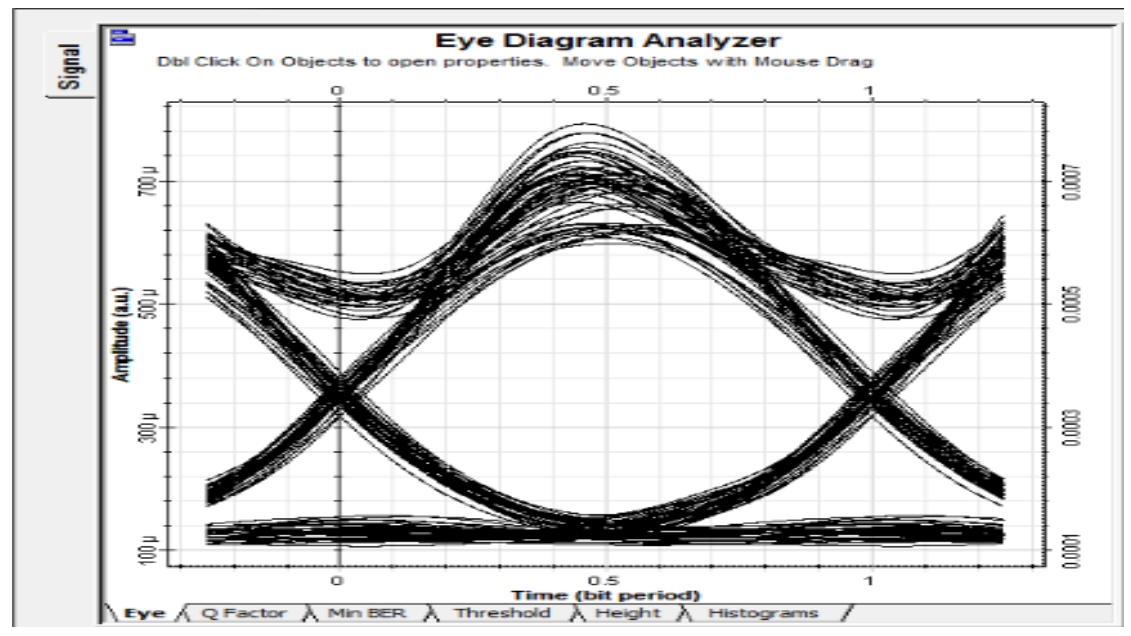

Figure 6. Eye Diagram of Channel 1 
At Frequency of $193.1 \mathrm{THz}$, the transmission distance of $1203 \mathrm{~km}$ with Q- factor of 9.835 and BER of $10^{-23}$ is achieved.

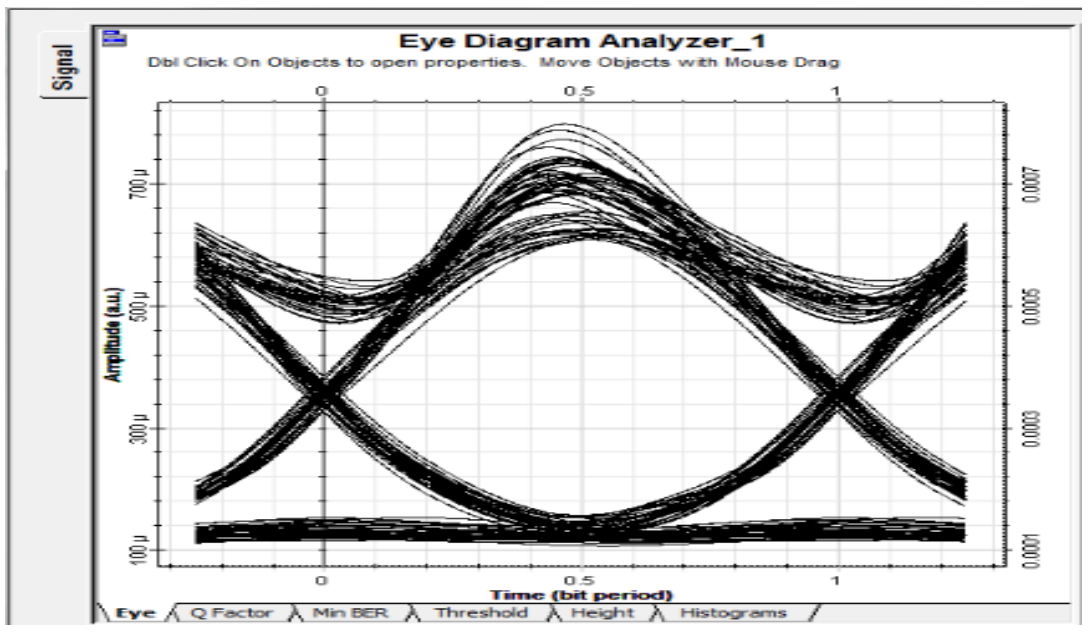

Figure 7. Eye Diagram at Channel 8

At frequency of $193.1 \mathrm{THz}$ the transmission distance of $1203 \mathrm{~km}$ with Q- factor of 19.56 and BER of $10^{-23}$ is achieved.

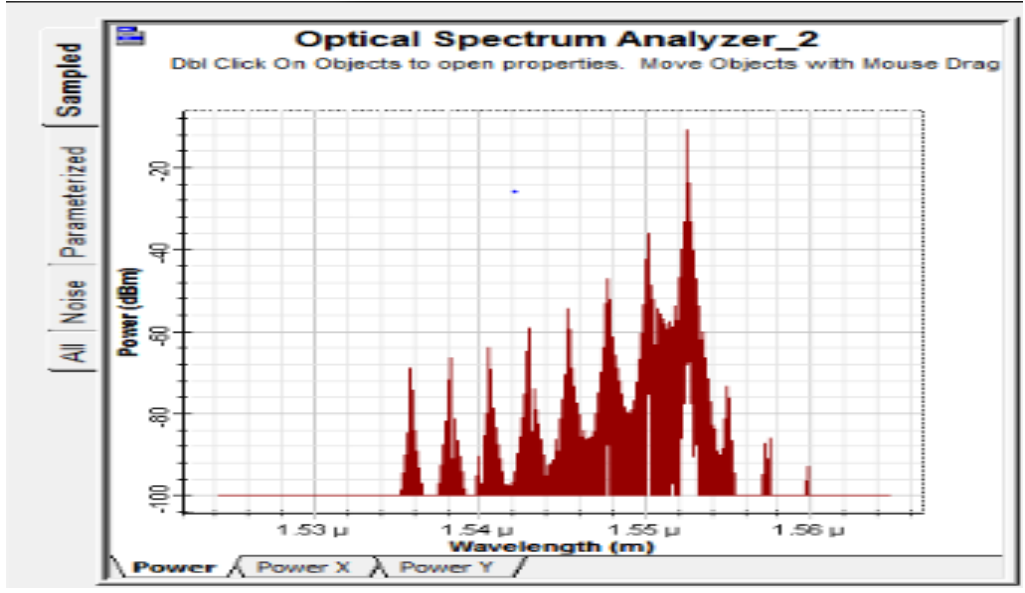

Figure 8. Optical Spectrum Analyzer of Channel 1 Operated at 193.1THz

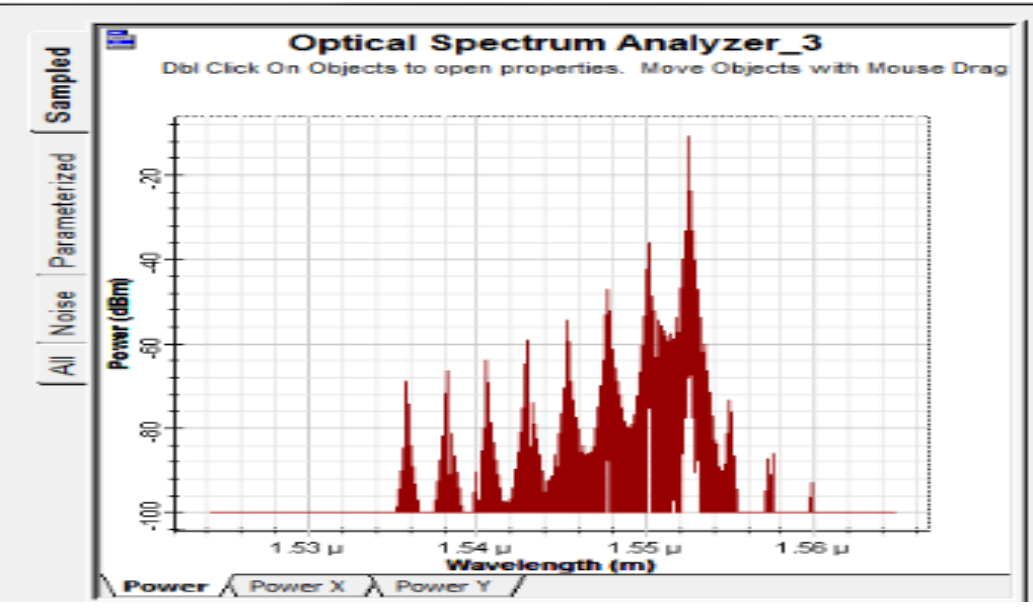

Figure 9. Optical Spectrum Analyzer of Channel 8 Operated at $195.2 \mathrm{THz}$ 
Table 1. Comparison $b / w ~ R Z$ and NRZ Format at Equal Channel Spacing of $300 \mathrm{GHz}$

\begin{tabular}{|c|c|c|c|c|}
\hline Frequency (THz) & \multicolumn{2}{|c|}{ RZ format } & \multicolumn{2}{c|}{ NRZ format } \\
\hline & Q factor & BER & Q factor & BER \\
\hline 193.1 & 9.8352 & $10^{-23}$ & 10.97 & $10^{-28}$ \\
\hline 193.4 & 8.5042 & $10^{-19}$ & 10.99 & $10^{-28}$ \\
\hline 193.7 & 9.8048 & $10^{-23}$ & 11.646 & $10^{-31}$ \\
\hline 194 & 9.0503 & $10^{-20}$ & 11.45 & $10^{-30}$ \\
\hline 194.3 & 8.8455 & $10^{-19}$ & 10.74 & $10^{-27}$ \\
\hline 194.6 & 9.2631 & $10^{-21}$ & 11.30 & $10^{-30}$ \\
\hline 194.9 & 9.587 & $10^{-22}$ & 11.11 & $10^{-29}$ \\
\hline 195.2 & 9.7762 & $10^{-23}$ & 10.90 & $10^{-28}$ \\
\hline
\end{tabular}

\section{Conclusion}

In this work, the simulation of $8 \times 10 \mathrm{Gbps}$ WDM system with equal channel spacing of $300 \mathrm{GHz}$ has been performed. It has been observed that for NRZ format, the system travels transmission distance of $962 \mathrm{~km}$ for NRZ and RZ format it covers $1203 \mathrm{~km}$. The two modulation formats have been numerically compared in terms of Q-Factor and BER. The presented results show that RZ format has given best performance as it travels larger distance that is $1203 \mathrm{~km}$ as compared to non return to zero format as dispersion is reduced to large extent using dispersion compensated fiber. Superior performance of RZ has been observed with a Q-factor of 9.833 and BER of $10^{-23}$. The eye diagrams shows value of threshold and height which results in improved synchronization in optical network.

\section{References}

[1] J. Lee, D. han and Y. Lee, "Optimization of $40 \mathrm{gbps}$ wdm system using super-gaussian RZ pulses", Journal of the Optical Society of Korea, vol. 12, (2008) December, pp. 226-231.

[2] A. Phogat, T. Gulathi and D. Malik, "BER and Q Factor estimation at $10 \mathrm{gbps}$ in hybrid system", international journal for advance research in engineering and technology, vol. 1, (2013) July, pp. 39-42.

[3] L. Li, C. Ze-Nan and D. Zhao, "Research on mixed data rate in wdm networks", Indonesian Journal of electrical engg, vol. 12, (2013) December, pp. 7431-7437.

[4] M. Bhutani, "Simulation and performance analysis of smf and mmf with varying length and different modulation pattern using dispersion compensation", International Journal of Computer Applications, vol. 35, (2011) December, pp. 16-20.

[5] M. I. Hayee and A. E. Willener, "NRZ versus RZ in 10-40 -gbps dispersion-manged wdm transmission systems", IEEE photon Technol., vol. 11, no.8, (1999) August, pp. 991-993.

[6] N. Amina and S. Salim, "Performance analysis of 8 channel dwdm system with $0.4 \mathrm{~nm}$ spacing using modulation format", International journal of engg., research and general science, vol. 3, April 15, pp. 923-927,

[7] B. Hu, W. Jing, W. Wei and R. Zhaol, "Analysis on dispersion compensation with def based on optisystem", IEEE, $2^{\text {nd }}$ International conference on industrial and information system, vol. 2, (2010) July, pp. 40-43.

[8] S. Singh and K. Kaur, "Analysis on dispersion compensattion of dwdm sustem with def and various modulation format", International Journal for Multi Disciplinary Engineering and Business Management, vol. 2, (2014) December, pp. 15-18.

[9] G. Keiser, "optical fiber communication", third edition, (2000).

[10] C. Chien and I. Lyubomirsky, "Comparison of rz versus NRZ pulse shapes for optical duobinary Transmission”, journal of lightwave technology, vol. 25, (2007) October, pp. 2953-2958.

[11] S. Olonkins, V. Bobrovs and G. Ivanovs, "Electronics Electrical Eng.", vol. 7, no. 133, (2012).

[12] G. Arora and S. Dewra, "International Journal of Electronics and Communication Engineering Research", vol. 1, no. 6, (2013).

[13] M. M. Lodro and M. A. Joyo, Proceedings of International Conference on Information and Computer Networks (ICICN), Singapore, (2012) February 26-28.

[14] V. Bobrovs, S. Olonkins, O. Ozolins, J. Porins and G. Lauks, "OSA Publications", $3^{\text {rd }}$ Fiber Optics in Access Network - FOAN, St Petersburg, Russian Federation, (2012) October 3-4. 